\title{
A Surgeon's handedness in direct anterior approach-hip replacement
}

\author{
Xiangpeng Kong ${ }^{1 \dagger}$, Minzhi Yang ${ }^{1,2+}$, Alvin Ong ${ }^{3}$, Renwen Guo ${ }^{1}$, Jiying Chen ${ }^{1}$, Yan Wang ${ }^{1 *}$ and Wei Chai ${ }^{{ }^{*}}$
}

\begin{abstract}
Background: The impact of handedness on clinical outcomes was easily overlooked in hip replacement. This study aimed to find whether the component positioning and hip function were affected by the handedness in total hip arthroplasty (THA) through direct anterior approach (DAA).

Methods: Total 102 patients who underwent bilateral DAA-THAs simultaneously between May 2016 and November 2018 in our institute were reviewed. All surgeries were operated by one right-handed surgeon. Their demographic, cup positioning, stem alignment, femoral stem fit, Harris hip score (HHS), intraoperative and postoperative complications were used to evaluate the role of handedness in DAA.

Results: The inclination of left cups was significantly larger than that of right cups (42.61 \pm 7.32 vs $39.42 \pm 7.19, p=$ 0.000 ). The stem fit of left femur was significantly larger than that of right femur ( $84.34 \pm 4.83$ vs $82.81 \pm 6.07, p=$ 0.043). No significant differences in safe zone ratio, HHS and complications between bilateral hips were found.

Conclusions: A surgeon's handedness had significant impact on cup's inclination and femoral stem fit in DAA-THA. However, there were no significant differences of cup malpositioning, stem alignment, hip function scores and complications between bilateral DAA-THAs.
\end{abstract}

Keywords: Handedness, Total hip arthroplasty, Direct anterior approach, Cup positioning, Femoral stem fit

\section{Background}

The significant influence of handedness on surgical procedures has been reported previously, including joint replacement [1-9]. However, the effect of handedness on total hip arthroplasty (THA) through direct anterior approach (DAA) has never been well defined or quantified.

In this study, we retrospectively analyzed the patients who underwent bilateral DAA-THAs in our institute. The primary aim was to find whether the component positioning between bilateral THAs had significant difference. The secondary aim was to explore whether the hip function between bilateral THAs were also affected by the handedness.

\footnotetext{
* Correspondence: wangyanguanjie@sina.com; chaiweiguanjie@sina.com ${ }^{+}$Xiangpeng Kong and Minzhi Yang are First authors

'Department of Orthopaedics, Chinese PLA General Hospital, No.28 Fuxing Road, Haidian, Beijing 100853, China

Full list of author information is available at the end of the article
}

\section{Patients and methods \\ Cohorts and clinical data}

The consecutive patients who underwent bilateral DAATHAs simultaneously between May 2016 and November 2018 in our institute were retrospectively reviewed. Inclusion criterion: 1 . bilateral THAs were performed through DAA simultaneously; 2. bilateral THAs were completed by one surgeon with the cementless acetabular cup (Pinnacle, Depuy, New Jersey, USA) and tapered femoral stem (Accolade II, Stryker, Mahwah, USA); 3. bilateral hips had the same stage of the same etiology (Crowe classification and Ficat classification) and bilateral acetabulum had similar bone mass $[10,11]$; 4 . neither hip had the deformity caused by previous surgery and trauma. Exclusion criterion: 1. periprosthetic joint infection (PJI) or periprosthetic fractures in the postoperative follow-up period; 2 . the follow-up period was shorter than 1 year. A total of 115 patients met the

(c) The Author(s). 2020 Open Access This article is licensed under a Creative Commons Attribution 4.0 International License, which permits use, sharing, adaptation, distribution and reproduction in any medium or format, as long as you give appropriate credit to the original author(s) and the source, provide a link to the Creative Commons licence, and indicate if changes were made. The images or other third party material in this article are included in the article's Creative Commons licence, unless indicated otherwise in a credit line to the material. If material is not included in the article's Creative Commons licence and your intended use is not permitted by statutory regulation or exceeds the permitted use, you will need to obtain permission directly from the copyright holder. To view a copy of this licence, visit http://creativecommons.org/licenses/by/4.0/ The Creative Commons Public Domain Dedication waiver (http://creativecommons.org/publicdomain/zero/1.0/) applies to the data made available in this article, unless otherwise stated in a credit line to the data. 
inclusion criterion and 102 patients were enrolled in this study finally (Fig. 1). The surgeon in this study has performed about 500 cases of DAA-THA and been defined as right-hander by the Edinburgh Handedness Inventory [12]. Institutional Review Board approval for this study was obtained (S2019-029-01).

\section{Surgical procedures}

Surgical techniques have been described in detail by one of our senior authors [13]. Right hips were operated firstly in all patients. Manual traction during right THA was likely to cause pelvic tilt. Prior to the left THA, the surgeon would correct the pelvic tilt in reference of bilateral anterior superior iliac spine. The surgeon aimed to place the cups at $15^{\circ}$ (anteversion) and $40^{\circ}$ (inclination), the stems for neural alignment and best filling. Every patient took the X-ray of pelvic in the operating room and the radiological method was standardized throughout the entire study. The X-ray beam centered over the pubic symphysis, pelvic tilt was corrected and bilateral legs were internally rotated. Until the X-ray indicated that pelvic position and femur rotation were normal, it was seen as standard.

\section{Follow-up and radiographic measurements}

The patients were followed at every year after surgery. The demographic and Harris hip score (HHS) of each patient were collected. The intraoperative and postoperative complications were defined as entering the incorrect interval during the exposure, severe vascular injury (vascular surgeon intervention required), intraoperative periprosthetic femoral fractures, lateral femoral cutaneous nerve (LFCN) palsy, dislocation, heterotopic ossification $(\mathrm{HO})$ and aseptic loosening [14].

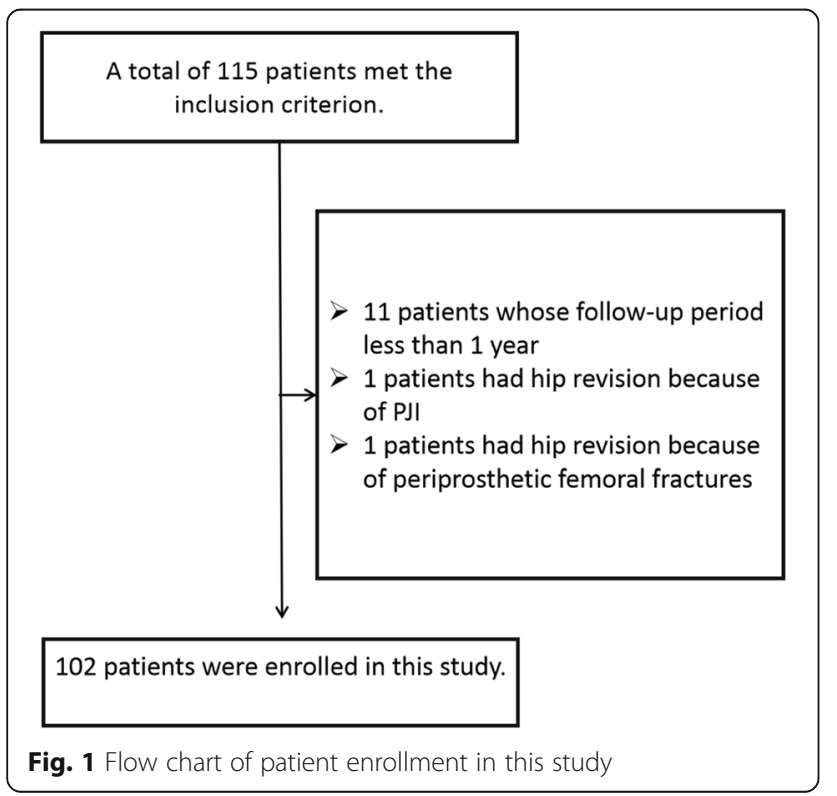

The ceramic femoral head was used to calibrate the radiographs to eliminate magnification error. Postoperative radiographic evaluation: Cup positioning was measured with Orthoview Software (Version 6.6.1, Materialise, Leuven, Belgium). The accuracy of this software for measuring the anteversion and inclination of acetabular cups has been validated $[8,15]$. Anteversion was the angle between the short and long axes of the ellipse projected by the cup (antevesions or retroversion of acetabular cups were affirmed by lateral X-ray of hips) (Fig. 2). Inclination of cup was the angle between the cup's long axis and the trans-teardrop line (Fig. 2) [16]. Stem alignment was assessed by measuring the angle between the axis of stem and femur (Fig. 3) [17]. Femoral stem fit was the average of three ratios of stem width to cavity diameter at proximal level, mid-stem and distal level (Fig. 3) $[18,19]$. Cup malposition was defined when its orientation was beyond Lewinnek safe zone (inclination: 30-50' anteversion: $5-25^{\circ}$ ) [20]. Stem malalignment was defined when its alignment was greater than $3^{\circ}[21,22]$.

All of the measurements were initially performed in a random order independently by two trained joint surgery residents (KXP and YMZ), who then made the measurements again after 2 weeks. The average of four values was regarded as the final result.

\section{Statistical analysis}

All statistical analyses were performed by SPSS version 22 (Inc., Chicago, IL, USA). Data showed as mean \pm standard deviation (SD) (normal distribution or near normal distribution). Measurement data were analyzed by paired-samples T-test or rank sum test. Count data were analyzed by chi-square test or Fisher's exact test. A $p$-value $<0.05$ was considered significant for all analyses. The intraclass correlation coefficient (ICC) was used to determine variations in different measurements. The intra-observer and inter-observer agreements were found to have nearly perfect reliability for all of the measurements $(\mathrm{ICC}>0.81)$.

\section{Results}

Of the remaining 102 patients, 94.12\% (96/102) were osteonecrosis of the femoral head (ONFH), 2.94\% (3/ 102) were developmental dysplasia of the hip (DDH) and 2.94\% (3/102) were rheumatoid arthritis (RA). Their demographics and follow-up periods showed in Table 1.

The inclination of left cups was significantly larger than that of right cups $(42.61 \pm 7.32$ vs $39.42 \pm 7.19, p=$ $0.000)$. The stem fit of left femur was significantly larger than that of right femur $(84.34 \pm 4.83$ vs $82.81 \pm 6.07$, $p=0.043)$. There were no significant differences in anteversion, cup malposition, stem alignment and HHS between bilateral DAA-THAs. 


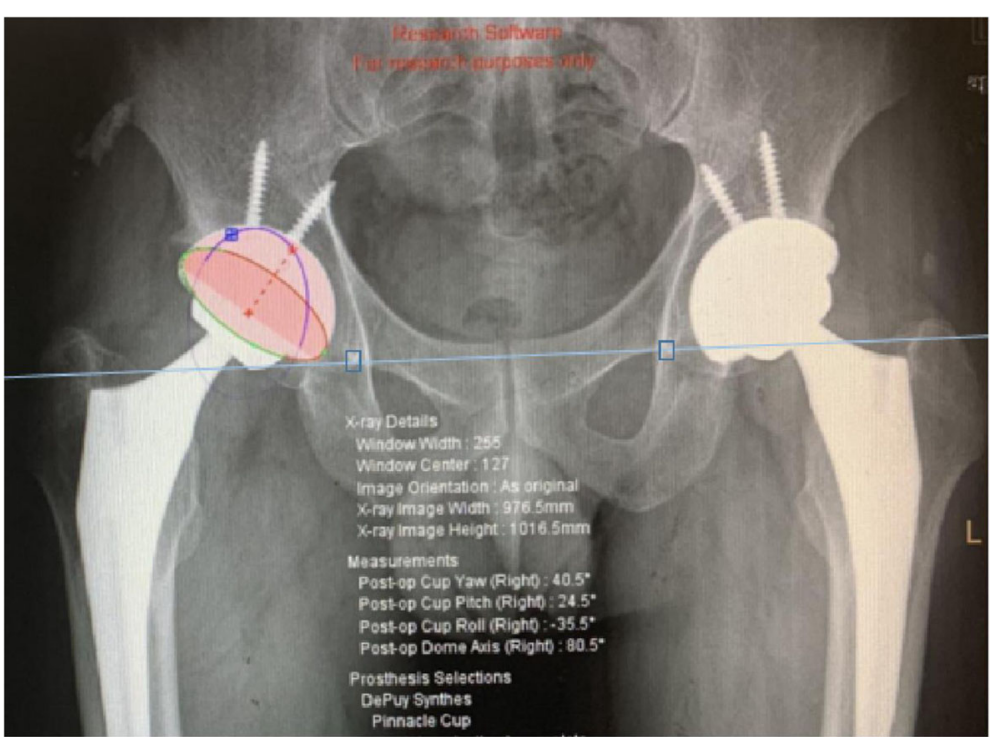

Fig. 2 The method of measuring anteversion and inclination of acetabular cups on plain radiograph of pelvic with Orthoview Software

When comparing with Lewinnek safe zone, 26.47\% (27/ 102) cups in left side and $18.63 \%(19 / 102)$ cups in right side weren't placed in the safe zone, but the difference wasn't significant ( $p=0.180)$ (Fig. 4). All of the prosthetic parameters and function scores showed in Table 2.
Among the consecutive case series, the overall incidence of complication were $16.18 \%(33 / 204)$, and that left and right THA were respectively $16.67 \%$ $(17 / 102)$ and $15.69 \%(16 / 102)$, which was showed in Table 3.

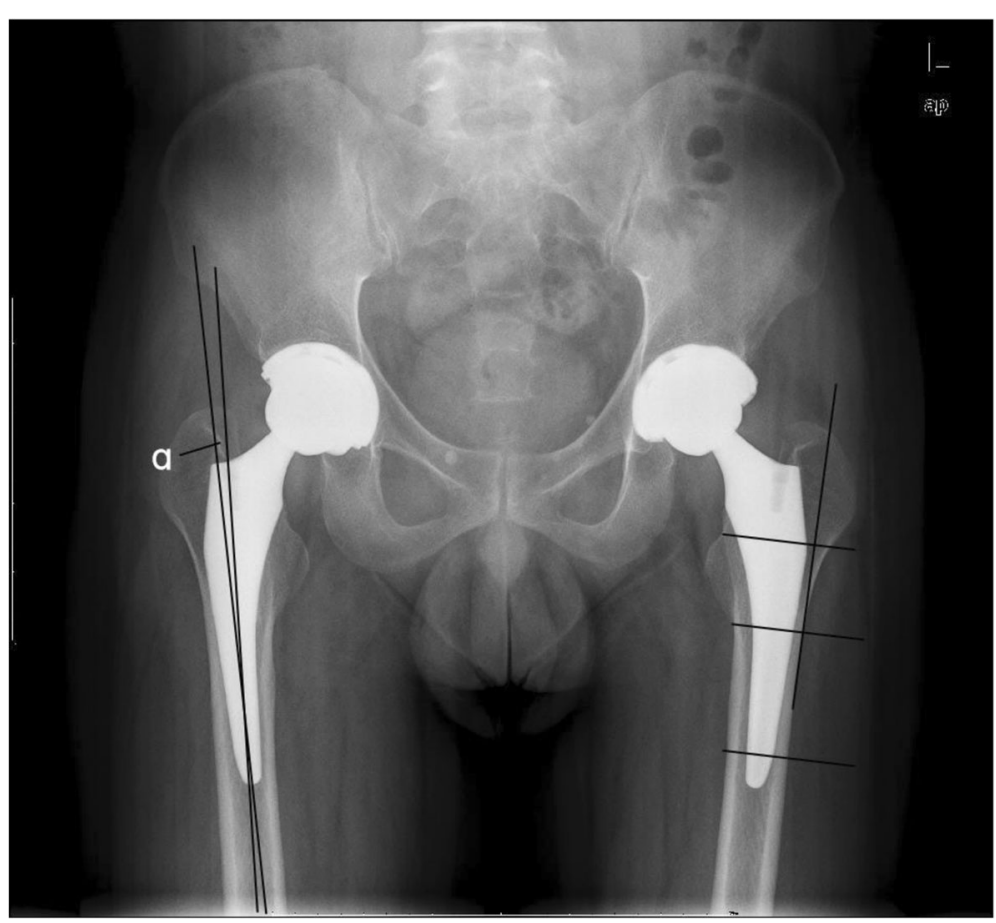

Fig. 3 Stem alignment was assessed by measuring the angle " $a$ " between the axis of stem and femur in right hip. Femoral stem fit was assessed by calculating the ratio of stem width to cavity diameter at three level: proximal level (parallel to the upper border of the lesser trochanter); midstem and distal level $(1 \mathrm{~cm}$ proximal to the distal end of stem). The three levels were perpendicular to the tangent line of lateral femoral cortex in left hip 
Table 1 The demographic data and follow-up periods of the one hundred and two patients

\begin{tabular}{ll}
\hline Patients & Data \\
\hline Female: male & $43: 59$ \\
Age (years) & $43.39 \pm 11.91$ \\
Height $(\mathrm{cm})$ & $166.65 \pm 8.53$ \\
Weight $(\mathrm{kg})$ & $63.20 \pm 10.40$ \\
BMl $\left(\mathrm{kg} / \mathrm{m}^{2}\right)$ & $22.68 \pm 2.79$ \\
Follow-up period (months) & $17.11 \pm 2.58$ \\
\hline BMI body mass index &
\end{tabular}

In the group of left hips, two hips had incorrect exposure. Two hips injured femoral profound arteries, and one was sewed immediately by the vascular surgeon and another was treated by the interventional surgery on the postoperative second day. One hip had periprosthetic femoral fracture and 12 patients reported LFCN palsy.

In the group of right hips, one hip had incorrect exposure. Three hips had periprosthetic femoral fracture during operation, one of them fractured in the femoral calcar and two fractured in the greater trochanter. Nine patients reported LFCN palsy. One case had dislocation in the postoperative seventh month, and treated by manipulative reduction and wearing brace for 2 months. Both two cases of $\mathrm{HO}$ were found in postoperative 1 year and classified as the Brooker grade II.

\section{Discussion}

In this study, the significant impact of handedness on surgical outcomes was found in DAA, although these surgeries were performed by an experienced surgeon, who has got through the learning curve. Cup inclination in the dominant side is more reproducible to pre-operative plan and femoral stem fit in the nondominant side was tighter than the contralateral side, but there were no significant differences of hip function scores and complications between bilateral DAATHAs.

Handedness is the human's laterality of using one hand more than the other [23]. Because human bones are symmetrically distributed, the impact of surgeon' handedness on orthopedic surgery may be even greater than non-orthopedic surgery.

So far as we know, only one study focused on the impact of handedness on DAA-THA [24]. In 2019, Crawford et al. compared the acetabular component position differences between right and left hips for a right-hand dominant surgeon. In their study, right hips had a significantly lower abduction and less combined Lewinnek outliers through DAA. However, as the most difficult part of the operation, whether the femoral side was affected by the handedness was ignored. And they also failed to prove the comparability between groups. In this study, we enrolled the patients who underwent the simultaneous bilateral THA to eliminate the inherent demographic differences between the patients who underwent unilateral THA. Other strength of this study

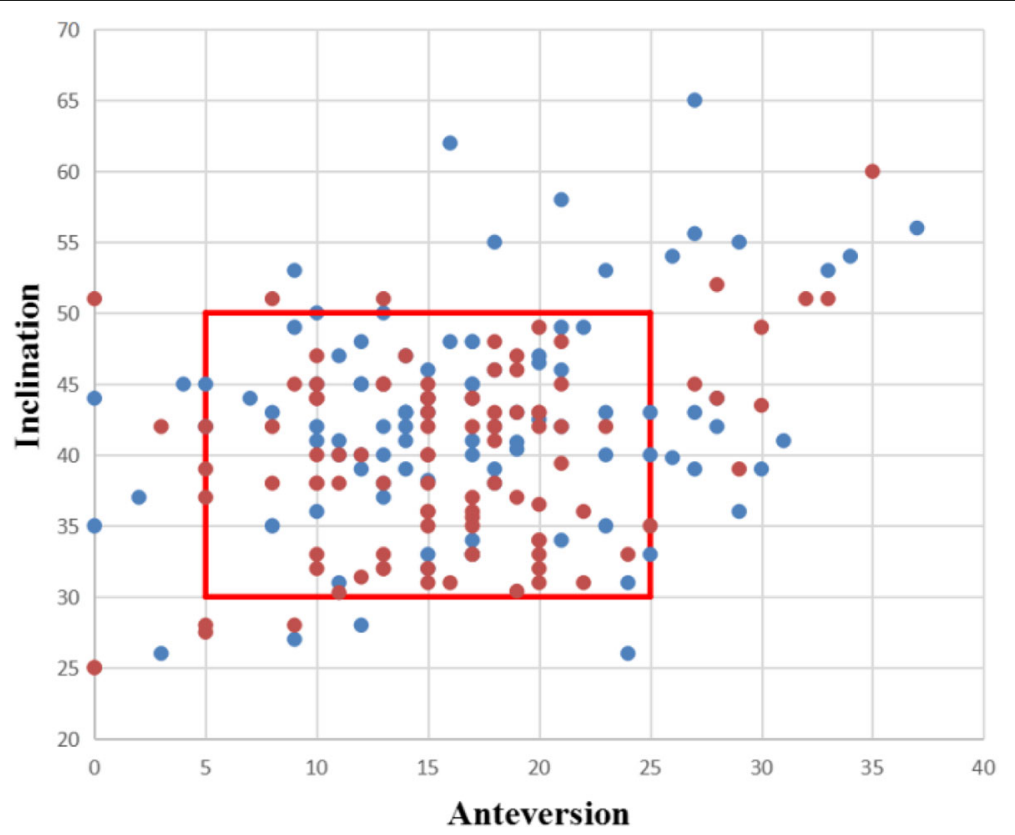

Fig. 4 A scatter plot of anteversion and inclination of acetabular cup refers to the Lewinnek safe zone. Left: blue plot; right: red plot 
Table 2 Comparison of the prosthetic parameters and function scores between bilateral hips

\begin{tabular}{|c|c|c|c|}
\hline Prosthetic parameters and function scores & Left & Right & P \\
\hline Anteversion $\left(^{\circ}\right)$ & $16.91 \pm 7.49$ & $15.79 \pm 6.99$ & $0.235^{\mathrm{a}}$ \\
\hline Inclination $\left(^{\circ}\right)$ & $42.61 \pm 7.32$ & $39.42 \pm 7.19$ & $0.000^{\mathrm{a}}$ \\
\hline Cup malposition & $27 / 102$ & $19 / 102$ & $0.180^{b}$ \\
\hline \multicolumn{4}{|l|}{ Stem alignment } \\
\hline neural & 94 & 91 & \multirow[t]{3}{*}{$0.648^{b}$} \\
\hline varus & 4 & 7 & \\
\hline valgus & 4 & 4 & \\
\hline Femoral stem fit (\%) & $84.34 \pm 4.83$ & $82.81 \pm 6.07$ & $0.043^{\mathrm{a}}$ \\
\hline $\mathrm{HHS}$ & $93.01 \pm 3.94$ & $94.33 \pm 4.00$ & $0.180^{\mathrm{a}}$ \\
\hline
\end{tabular}

HHS Harris hip score. ${ }^{a}$ paired-samples T-test or rank sum test. ${ }^{b}$ chi-square test or Fisher's exact test

was that we also analyzed the potential impact of handedness on the femur in DAA-THA.

When performing DAA-THA, the surgeon's standing position will directly affect surgical procedures. During the operation on the acetabulum, the surgeon was always toward the patient's head. During the operation on the femur, the surgeon turned towards the patient's foot. This might result in the opposite effect of handedness on the femur and acetabulum in the same side.

During DAA-THA, the surgeon usually defined the anteversion by taking the operating table as reference. However, the reference for inclination was the virtual horizontal body axis. Under the action of pulling femur, the patient's body position often changed imperceptibly relative to the operating table. This deceptive position makes it harder for the surgeon to judge the inclination from an unaccustomed perspective. That's why the inclination was more susceptible to the surgeon's handedness.

It is worth noting that this was the first study on the influence of handedness on the femoral stem in THA, whether DAA or other approaches. Elevation of the femur is the most important and difficult step in the DAA-THA [13]. Exposure of proximal femur was laboursome and its freedom was significantly less than that in posterolateral approach (PA)-THA, the surgeon had to handle the femur under unaccustomed gesture and perspectives. The limitation of field of vision and inconvenience of manual manipulation aggravated the impact of handedness. Interestingly, because the hands were forced to cross, the right-handed surgeon was more awkward to expose the right femur and implant the right stem. Poor (non-tight) initial fit and fill of the femoral stem were associated with thigh pain and component loosening, so the inferior femoral stem fit of right side might decrease the survivorship in longterm follow-up [19].

Although the surgeon's handedness did have significant impact on the position of prosthesis, no such significant differences of joint function score and complications were found. The negative results might be largely on account of the small sample size and short follow-up.

Awareness of handedness having significant impact on DAA was the first and most important step. Intraoperative fluoroscopy, navigation, and robot might help to eliminate the bad influence of handedness $[25,26]$. The indications of DAA-THA must be strictly controlled, which included the diagnosis, BMI and range of motion. Obesity is a relative contraindication to DAA, but the criteria of contraindication about BMI was disputable [27, 28].

This study has several limitations. Firstly, the surgeon in this study was right-handed and the results in this study could be a single surgeon's deviation rather than general phenomenon. The left-handed surgeons should be included in the future to reduce the inherent bias. In addition, more refined handedness loyalty and usage preference should be included to analyze its contribution concretely. Secondly, the negative results might be

Table 3 Comparison of the intraoperative and postoperative complications between bilateral hips

\begin{tabular}{|c|c|c|c|c|c|c|c|}
\hline \multirow[t]{2}{*}{ Complications } & \multicolumn{3}{|l|}{ Intraoperative } & \multicolumn{3}{|c|}{ Postoperative } & \multirow[t]{2}{*}{ Total } \\
\hline & Incorrect exposure & Severe vascular injury & PFF & LFCN palsy & Dislocation & $\mathrm{HO}$ & \\
\hline Left & 2 & 2 & 1 & 12 & 0 & 0 & 17 \\
\hline Right & 1 & 0 & 3 & 9 & 1 & 2 & 16 \\
\hline$P$ & - & - & - & - & - & - & $0.849^{b}$ \\
\hline
\end{tabular}

PFF periprosthetic femoral fracture, LFCN lateral femoral cutaneous nerve, $\mathrm{HO}$ heterotopic ossification. ${ }^{\mathrm{a}}$ paired-samples T-test or rank sum test. ${ }^{\mathrm{b}}$ chi-square test or Fisher's exact test 
largely on account of the small sample size and short follow-up. More patients and longer follow-up period are needed to increase the study's persuasiveness. Thirdly, although we reconfirmed the pelvic position before left THA, the position of patients and pelvis could have changed after the first procedure and this could influence the cup positioning of the second procedure. Fourthly, the measurement of cup positioning was based on the supine anteroposterior pelvic radiograph, which might be inferiorer than the accuracy of computed tomography $(\mathrm{CT})$. However, measurements based on radiograph have been proven to have excellent correlation to CT scan [29]. And the Lewinnek safe zone was also defined by the radiograph [20].

\section{Conclusions}

Surgeon's handedness had significant impact on cup's inclination and femoral stem fit in DAA-THA. However, there were non-significant findings on anteversion, cup malposition, stem alignment and safe zones.

\section{Abbreviations \\ THA: Total hip arthroplasty; DAA: Direct anterior approach; HHS: Harris hip score; HO: Heterotopic ossification; SD: Standard deviation; ICC: Interclass correlation coefficient; DDH: Developmental dysplasia of the hip; RA: Rheumatoid arthritis; BMI: Body mass index; PFF: Periprosthetic femoral fracture; LFCN: Lateral femoral cutaneous nerve; PA: Posterolateral approach; CT: Computerized tomography}

\section{Acknowledgements}

The medical ethics committee of General Hospital of Chinese PLA approved the study. All procedures were conducted in compliance with the guidelines of the Declaration of Helsinki. The patients were informed consent prior to their participation in the study.

\section{Authors' contributions}

All authors have made substantial contributions to: (1) the conception and design of the study,acquisition of data, or analysis and interpretation of data, (2) drafting the article or revising it critically for important intellectual content, (3) final approval of the version to be submitted. XK and MY: primarily responsible for all computational analyses in the article and the drafting of the manuscript. XK and MY contributed to this work equally and both of them were co-first author. WC and YW: primarily responsible for oversight of the research project, including all data acquisition and analysis, and manuscript preparation and approval. WC and YW contributed to this work equally and both of them were co-corresponding author. AO, RG and JC: revised the manuscript and helped perform the analysis with constructive discussions.

\section{Funding}

None

\section{Availability of data and materials}

The datasets used and/or analyzed during the current study are available from the corresponding author on reasonable request.

\section{Ethics approval and consent to participate}

The medical ethics committee of Chinese PLA General Hospital approved the study. All procedures were conducted in compliance with the guidelines of the Declaration of Helsinki. The patients were written informed consent that their clinical images and medical records for scientific report.

\section{Consent for publication}

We have obtained the written consent for publication.

\section{Competing interests}

The authors declare that they have no competing interests.

\section{Author details}

'Department of Orthopaedics, Chinese PLA General Hospital, No.28 Fuxing Road, Haidian, Beijing 100853, China. ${ }^{2}$ Nankai University, No.94 Weijin Road, Nankai, Tianjin 300071, China. ${ }^{3}$ The Rothman Institute, Thomas Jefferson University, 2500 English Creek Avenue, Building 1300 Egg Harbor Township, Philadelphia, PA, USA.

Received: 13 February 2020 Accepted: 28 July 2020

Published online: 03 August 2020

\section{References}

1. Samir M, Lotke Paul A. Impact of surgeon handedness and laterality on outcomes of total knee arthroplasties: should right-handed surgeons do only right TKAs? Am J Orthop. 2007;36:530-3.

2. Kyle L, Fan Kenneth L, Black Cara K, et al. Does surgeon handedness or experience predict immediate complications after mastectomy? A critical examination of outcomes in a single health system. Breast J. 2020;26:376-83

3. Imad AL, Hind AM, Sunyoung M. "I am a lefty in a right-handed world": Qualitative analysis of clinical learning experience of left-handed undergraduate dental students. Eur J Dent Educ. 2019:23:316-22.

4. Adusumilli Prasad S, Kell C, Chang JH, et al. Left-handed surgeons: are they left out? Curr Surg. 2004;61:587-91.

5. Moorthy K, Munz Y, Dosis A, et al. Dexterity enhancement with robotic surgery.[J]. Surg Endosc. 2004;18:790-5.

6. Phillip M, Kerbl David C, Lee Jason Y. The da Vinci( $\left.{ }^{\oplus}\right)$ Surgical System overcomes innate hand dominance. J Endourol. 2011;25:1385-8.

7. Varol C, Tan U, Recep O, et al. Right- and left-handed dentists in periodontal therapy. Int J Neurosci. 2002;112:1-14

8. Xinggui $S$, Ming $N$, Heng $L$, et al. Is the cup orientation different in bilateral total hip arthroplasty with right-handed surgeons using posterolateral approach? J Orthop Surg Res. 2018;13:123. https://doi.org/ 10.1186/s13018-018-0789-y.

9. Pennington $\mathrm{N}$, Redmond $\mathrm{A}$, Stewart $\mathrm{T}$, et al. The impact of surgeon handedness in total hip replacement.[J]. Ann R Coll Surg Engl. 2014;96: 437-41.

10. Crowe JF, Mani VJ, Ranawat CS. Total hip replacement in congenital dislocation and dysplasia of the hip.[J]. J Bone Joint Surg Am. 1979; 61:15-23.

11. Ficat RP. Idiopathic bone necrosis of the femoral head. Early diagnosis and treatment.[J]. J Bone Joint Surg Br. 1985;67:3-9.

12. Oldfield RC. The assessment and analysis of handedness: the Edinburgh inventory. Neuropsychologia. 1971;9:97-113.

13. Post Zachary D, Fabio O, Claudio D-L, et al. Direct anterior approach for total hip arthroplasty: indications, technique, and results. J Am Acad Orthop Surg. 2014;22:595-603.

14. Brooker AF, Bowerman JW, Robinson RA, et al. Ectopic ossification following total hip replacement. Incidence and a method of classification. J Bone Joint Surg Am. 1973;55:1629-32.

15. Camilo R, Javad P, Kurtz Steve M, et al. The noisy ceramic hip: is component malpositioning the cause? J Arthroplast. 2008;23:643-9.

16. Murray DW. The definition and measurement of acetabular orientation. J Bone Joint Surg Br. 1993;75:228-32.

17. Hirohito A, Takashi S, Masaki T, et al. Difference in stem alignment between the direct anterior approach and the Posterolateral approach in Total hip Arthroplasty. J Arthroplast. 2015;30:1761-6.

18. Kim YH, Kim VE. Uncemented porous-coated anatomic total hip replacement. Results at six years in a consecutive series. J Bone Joint Surg Br. 1993;75:6-13.

19. van der Wal BCH, de Kramer BJ, Grimm B, et al. Femoral fit in ABG-II hip stems, influence on clinical outcome and bone remodeling: a radiographic study.[J]. Arch Orthop Trauma Surg. 2008;128:1065-72.

20. Lewinnek GE, Lewis JL, Tarr R, et al. Dislocations after total hip-replacement arthroplasties.[J]. J Bone Joint Surg Am. 1978;60:217-20.

21. Wang $H$, Jiaao $G$, Xin $L$, et al. Variation in greater trochanteric lateroversion: a risk factor for femoral stem varus in total hip arthroplasty.[J]. Hip Int. 2020; 30:33-9. 
22. Vresilovic EJ, Hozack WJ, Rothman RH. Radiographic assessment of cementless femoral components. Correlation with intraoperative mechanical stability.[J]. J Arthroplast. 1994;9:137-41.

23. Hanna GB, Drew T, Clinch P, et al. Psychomotor skills for endoscopic manipulations: differing abilities between right and left-handed individuals. Ann Surg. 1997;225:333-8.

24. Crawford David A, Adams Joanne B, Hobbs Gerald R, et al. Surgical approach and hip laterality affect accuracy of Acetabular component placement in primary Total hip Arthroplasty. Surg Technol Int. 2019;35:377-85.

25. Michael N, Eckart M, Martin $\mathrm{K}$, et al. Reduced variability in cup positioning: the direct anterior surgical approach using navigation. Acta Orthop. 2008;79: 789-93.

26. Bradley Michael P, Benson Jessica R, Muir Jeffrey M. Accuracy of Acetabular Component Positioning Using Computer-assisted Navigation in Direct Anterior Total Hip Arthroplasty. Cureus. 2019;11:e4478.

27. Martin Christopher T, Pugely Andrew J, Yubo G, et al. A comparison of hospital length of stay and short-term morbidity between the anterior and the posterior approaches to total hip arthroplasty. J Arthroplast. 2013;28: 849-54.

28. Workgroup of the American Association of Hip and Knee Surgeons Evidence Based Committee. Obesity and total joint arthroplasty: a literature based review. J Arthroplasty. 2013;28:714-21.

29. Lu M, Yi-Xin Z, Hui D, et al. Reliability and validity of measuring acetabular component orientation by plain anteroposterior radiographs. Clin Orthop Relat Res. 2013;471:2987-94.

\section{Publisher's Note}

Springer Nature remains neutral with regard to jurisdictional claims in published maps and institutional affiliations.

Ready to submit your research? Choose BMC and benefit from:

- fast, convenient online submission

- thorough peer review by experienced researchers in your field

- rapid publication on acceptance

- support for research data, including large and complex data types

- gold Open Access which fosters wider collaboration and increased citations

- maximum visibility for your research: over $100 \mathrm{M}$ website views per year

At $\mathrm{BMC}$, research is always in progress.

Learn more biomedcentral.com/submissions 